\title{
Preparing pre-service mathematics teachers for STEM education: an analysis of lesson proposals
}

\author{
Christer Bergsten ${ }^{1} \cdot$ Peter Frejd $^{1}$
}

Accepted: 6 July 2019 / Published online: 13 July 2019

(c) The Author(s) 2019

\begin{abstract}
Based on an investigation of research literature on the role of mathematics within the context of STEM education and twentyfirst century skills, this explorative study presents and analyses 19 pre-service teachers' lesson proposals for innovative STEM activities in secondary mathematics classrooms. Drawing on a categorisation of twenty-first century skills and key concepts from Realistic Mathematics Education and Basil Bernstein's writings, the analysis indicated a use of detailed instructions regarding what students should do but unspecified criteria for their expected knowledge productions. Rather than serving as a digital tool for problem solving, programming was used for the purpose of generalising students' conceptual knowledge in mathematics. At the same time a focus on modelling and applications in the STEM activities tended to weaken the disciplinary character of mathematics. The learning of various twenty-first century skills was promoted to different extents. The study raises a discussion of affordances and constraints regarding students' access to mathematical knowledge through different modes of integration of mathematics and other STEM subjects aiming to support the development of twenty-first century skills.
\end{abstract}

Keywords STEM education · Twenty-first century skills · Pre-service teachers · Mathematical modelling · Horizontal and vertical mathematisation · Classification and framing

\section{Introduction}

Arguments have been put forward that current education does not prepare students "for the demands of the twentyfirst century workplace and world" (Gravemeijer et al. 2017, p. 120). New technological inventions are changing the way we live, learn and work, impacting on the skills required "to be effective workers and citizens in the knowledge society of the twenty-first century" (Ananiadou and Claro 2009, p. 8), including learning and innovation skills, information, media and technology skills, and life and career skills (P21 2009). Internationally, researchers call for explorations of teaching and learning methods aiming to develop the twenty-first century skills and strengthen the relation between science, technology, engineering, and mathematics (STEM) (e.g., Frejd 2017; Kertil and Gurel 2016). In particular, one faces the problem of preparing and implementing cross-curricular

Peter Frejd

peter.frejd@liu.se

1 Linköping University, Linköping, Sweden activities for integrated STEM education within the current school organization (Corlu et al. 2014; Honey et al. 2014). However, there seems to be a dilemma here for mathematics teachers; on the one hand, a pedagogy for developing students' twenty-first century skills through STEM education would include an integration of up to four specific disciplines into a scientific inquiry or project; on the other hand, it is vital to make mathematics itself visible and not just let it serve the other subjects (English 2016).

This study aims to address this dilemma by analysing submitted home assignment reports from a STEM seminar for pre-service mathematics teachers, designed to prepare them for STEM education within the context of twenty-first century skills. The reports included lesson plans with STEM activities developed by the participants. The seminar was developed drawing on arguments from research literature that mathematical modelling is a bridge to STEM education (Kertil and Gurel 2016) and that professional modellers and engineers rely on programming and new technologies for their work (Frejd and Bergsten 2016). One rationale for developing the STEM seminar was that recently, programming was included in the subject syllabus for mathematics in upper secondary school 
in Sweden to better prepare students for the future (Skolverket 2017). While the syllabus does not provide clear descriptions for teachers of how it could be implemented, programming is being associated with using or developing codes as a part of the mathematical problem solving process (Skolverket 2017). As modelling activities are not emphasised in current mathematics teaching (Stillman et al. 2015), and do not seem to be very 'authentic' seen from the perspective of professional modellers and engineers (Frejd and Bergsten 2016; Gainsburg 2013), there is an important gap to fill with respect to innovative teaching practice. While acknowledging that a teaching intervention always is influenced by its design and the background of the participants, an analysis of pre-service teachers' lesson plans may inform researchers and policy makers about affordances and constraints of mathematics as an enabler of STEM pedagogies in the perspective of twenty-first century skills. Our study was guided by the following research questions:

RQ1 How can the activities within pre-service teachers' lesson proposals designed to guide the learning of STEM content be characterised?

RQ2 How do the mathematical content and work set out in the proposals support the learning of STEM content?

RQ3 To what extent do the lesson proposals have a potential to promote the learning of twenty-first century skills?

The pre-service teachers participating in the study belong to a generation that grew up in the Information Age and have chosen to educate themselves for the teaching of mathematics (along with a second subject) in the twenty-first century. Their proposals for STEM activities for use in mathematics classrooms therefore have a particular interest and will in our analysis also be discussed regarding their potential to promote the learning of twenty-first century skills.

In Sect. 2 the key notions of STEM education and twentyfirst century skills are examined to provide a conceptual basis for the empirical part of the study as well as the ensuing discussion. Section 3 then builds on this conceptual basis for the design and method of analysis of the STEM seminar, drawing also on theoretical notions from Realistic Mathematics Education and Basil Bernstein's work. The empirical data are then presented and analysed in Sect. 4, followed by an overall discussion of the study and its implications (Sect. 5).

\section{STEM education and twenty-first century skills}

To improve the quality of teaching and learning of science, technology, engineering, and mathematics (STEM), in the beginning of this millennium the promotion of
"STEM education" was initiated by the National Science Foundation (Holmlund et al. 2018). As this 'movement' has grown and gained international recognition (STEM n.d.), the notion of STEM education is now used in many countries (Kertil and Gurel 2016). Its close connection to competition within a global economy is evident from the following definition:

STEM education is an interdisciplinary approach to learning where rigorous academic concepts are coupled with real world lessons as students apply science, technology, engineering, and mathematics in contexts that make connections between school, community, work, and the global enterprise enabling the development of STEM literacy and with it the ability to compete in the new economy. (Southwest Regional STEM Network 2009, p. 3, cited in Holmlund et al. 2018, p. 2).

However, how to characterize STEM education and its impact on student abilities remains debated (Holmlund et al. 2018). With reference to a sample of research literature, it could be characterized by the following:

- Instructional practices motivating students to learn science and mathematics (Holmlund et al. 2018),

- student learning by the use of interdisciplinary activities related to real world situations (Peters-Burton et al. 2014);

- problem- and project-based learning (Peters-Burton et al. 2014),

- developing twenty-first century skills (Gravemeijer et al. 2017; P21 2009),

- collaboration with STEM professionals and use of innovative technologies within classroom activities (Holmlund et al. 2018),

- preparation of all students for global citizenry (Kennedy and Odell 2014).

STEM education can be based on a complete (new) curriculum or on an integration of STEM activities in the existing curriculum. The latter approach is used with different levels of integration ranging from disciplinary (separated), multidisciplinary (themes), interdisciplinary (linked concepts and skills), to transdisciplinary (linked concepts applied in projects and realistic problems) integration (English 2016, adapted from Vasquez et al. 2013). The integration of STEM activities in the classroom may vary depending on the underlying aims (Leung 2018). For example, the two models content integration (content from at least two subjects are covered) and context integration (using context from one subject for learning another subject while maintaining the rigour of the latter) may be used (Kertil and Gurel 2016, referring to Roehrig 2012). 
Referring to different teaching traditions in STEM disciplines, Leung (2018) identified three pedagogical approaches used in STEM education, inquiry-based learning, modeling, and tool-based pedagogy, and drew on these to develop a hybrid, boundary pedagogy. Several features of this approach, including contingency, uncertainty and ambiguity, making mistakes, applicability and extension, and refinement and modification, would traditionally not be endorsed in the disciplinary classrooms (pp. 15-17).

Even if science and technology are overrepresented in research literature about STEM education compared to mathematics (English 2016), research literature in mathematics education addressing STEM education has gained momentum. However, according to Fitzallen (2015) it does not "exemplify the way in which mathematics can influence and contribute to the understanding of the ideas and concepts of other STEM disciplines" (p. 241). To advance STEM integration, English (2016) identifies a "need to focus on both core content knowledge and interdisciplinary processes" (p. 3). She also remarks, though, that "mathematics achievement is difficult to promote through STEM integration" (p. 4, referring to Honey et al. 2014). While concepts and notions from other disciplines appear also in mathematics, within the school discipline, mathematics student productions are commonly assessed by the legitimate principles of the discipline itself, while other disciplines are used as motivational contexts or areas for application of mathematical methods. In conceptualisations of STEM teaching, however, mathematics is seen mainly as an "enabler", which could be interpreted as a (general) tool for describing relations between quantifiable magnitudes and for computing critical values. Mathematics then takes on the role of a necessary knowledge base acquired before engagement in a STEM activity can be meaningful. The 'pay-off' for mathematics on behalf of the students would thus be found mainly through the experience of its use afforded by the activity. However, when focusing on contexts students do not necessarily discover the "power of mathematics" without explicit intervention from the teacher (Jablonka and Gellert 2012, p. 51).

These remarks raise questions about which mathematical content and abilities should be the focus in STEM education. Here Gravemeijer et al. (2017) offer three suggestions in terms of mathematical abilities required for the future society: applying/modelling, understanding and checking answers. Developing and applying mathematical models is a common practice in STEM-related work contexts, where the use of digital tools and programming is a central component (Frejd and Bergsten 2016). With new technology the understanding of mathematical concepts and algorithms has more impetus than procedural skills for producing correct answers, as it is indispensible for conceiving mathematics hidden in black boxes and checking computer outputs (cf.
Gravemeijer et al. 2017). As the suggestions by Gravemeijer et al. (2017, pp. 116-117) of mathematical content deemed relevant for a future involving digital technology involve mathematics beyond elementary levels, to include them in curricula or STEM activities at school would possibly require a reorganisation of more elementary levels of school mathematics.

According to Holmlund et al. (2018), a majority of the teachers and workers in STEM settings participating in their study included "students' opportunities to develop twentyfirst century skills" as a "salient" feature of STEM education (p. 12). However, different frameworks for twenty-first century skills have been launched (e.g., Binkley et al. 2012; P21 2009), some with connotations similar to constructs such as lifelong learning competences (OECD 2018). While these frameworks organise the endorsed competences under different types of categories, there is still a large overlap including critical thinking, creativity, problem solving, decision making, ICT and information literacy, communication, collaboration, citizenship, personal and social responsibility, and life and career skills. In addition to being used with different labels (such as competences, skills, or abilities) depending on underlying interests or approaches (e.g., neo-liberal, psychological, political, or ethical), in education these terms are used in curricula both as means and goals, in specific disciplines and generally. As signifiers their meanings therefore remain floating, reflecting the influence of different groups and agents in different contexts (cf. Laclau 2007). While each of them has been emphasised in different periods in twentieth century education, launching them as a package of essential twenty-first century skills can be seen as a phenomenon of the Zeitgeist of the new millennium.

Several of the twenty-first century skills listed above have been promoted in mathematics education research and pedagogic practice over the years, most notably problem solving, ICT, communication and collaboration. It has often been claimed that the study of mathematics also develops logical and critical thinking and general problem solving abilities, a view also found to be common among engineering students in an interview study by Bergsten and Jablonka (2013). A similar result was found in a recent survey reported in Inglis and Attridge (2016), who investigated the claim that mathematics is a formal discipline developing general thinking abilities useful throughout life. Their conclusions were partly confirmatory in the sense that "studying advanced mathematics does indeed develop some aspects of conditional reasoning" (p. 130).

With this background, the role of mathematics as an enabler of STEM pedagogies, taking twenty-first century skills into account, would depend on forms of integration and interpretations of twenty-first century skills, but could also be strengthened by its potential to stand as a formal discipline. In addition there are unresolved issues, such as 
how to prepare teachers as implementers of an integrated STEM education, how to develop the curricular materials needed, and how to implement an integrated curriculum without changing existing school organizational structures (Corlu et al. 2014).

\section{Methodology}

In the empirical part of this study a STEM seminar was designed and implemented, including a home assignment, within a regular course for prospective secondary school mathematics teachers enrolled in a teacher education programme at a Swedish university. The aim was to explore potential affordances and constraints of mathematics as an enabler of STEM pedagogies in the perspective of twentyfirst century skills. In this section the theoretical and analytical tools used for the analysis of the empirical data ensuing from the seminar are discussed, followed by a description of the seminar in terms of its background, design principles, and structure. Finally, the method of data analysis is presented.

\subsection{Theoretical and analytical tools}

When different disciplines, such as those implicated in STEM education, are simultaneously involved in a learning context it may not be clear to the student by which criteria their productions are to be evaluated. In our discussion of this issue, we use the language for describing the strength of borders between disciplines put forward in Bernstein's theory of pedagogic discourse (Bernstein 1996). In Bernstein's terms, dominant power relations are reflected in principles of knowledge classification described as "relations between categories, whether these categories are between agencies, between agents, between discourses, between practices" (Bernstein 1996, p. 20). With a low level of interaction between the categories knowledge classification is strong, while a high level of interaction indicates a weak classification. The latter would typically apply to project-work approaches in STEM education where different disciplines are being integrated. In pedagogic practice working with predominantly 'pure' mathematics the external classification is strong (that is, the border between mathematics and other disciplines is strong) even if the internal classification may be weak in terms of relations between mathematical subareas such as geometry and functions. For the characterisation of the pedagogic communication in which these discourses are put into practice, Bernstein (1996) uses the term framing with reference to the level of control of the student of this communication. While the teacher for example maintains a strong framing over the evaluation criteria, students may still have influence on the sequencing and time set out for a specific section of the discipline study (weak framing).

In our analysis we will also refer to the notions horizontal and vertical mathematisation, as conceptualised within Realistic Mathematics Education (RME; e.g., Treffers 1987), where the former models realistic situations by way of mathematical principles and symbols, while the latter reorganizes the mathematical knowledge itself. Here horizontal mathematisation involves a weak (external) classification of the mathematical knowledge, while the classification is strong in the case of vertical mathematisation.

For the design of the STEM seminar and the organisation of our discussion of twenty-first century skills in STEM education we drew on the four "groups" or categories of twenty-first century skills employed by Binkley et al. (2012, p. 36): ways of thinking (creativity and innovation; critical thinking, problem-solving, decision-making; learning to learn, metacognition), ways of working (communication; collaboration), tools for working (information literacy; ICT literacy), and skills for living in the world (citizenship; life and career; personal and social responsibility).

\subsection{The STEM seminar}

In response to a call for innovative teaching practices promoting students' twenty-first century skills (e.g., Binkley et al. 2012), a STEM seminar for pre-service mathematics teachers was developed with the aim of providing ideas and opportunities for critical reflections on pedagogies for STEM activities, including the development of their own (innovative) lesson plans. For the design and implementation of the seminar, we adapted parts of the paradigm in Educational Design Research, defined as

the systematic analysis, design and evaluation of educational interventions with the dual aim of generating research-based solutions for complex problems in educational practice, and advancing our knowledge about the characteristics of these interventions and the processes of designing and developing them. (Plomp 2013, p. 16).

The seminar was part of a regular course in mathematics education within a teacher education programme at a major Swedish university. The course integrates didactic theory and teaching practice, including topics such as lesson plans and assessment, comprising nine seminars (sessions) during 3 weeks, and 5 weeks of practicum. The STEM seminar took place in the ninth session attended by 20 pre-service secondary mathematics teachers. Due to institutional constraints no more seminar time was available within this course for focusing on one specific didactical theme such as STEM education. As work was required also before and after the seminar their actual time spent on 
the topic went far beyond the $90 \mathrm{~min}$ of attending the session. On the occasion of the seminar, the participants had attended the teacher education programme for two and a half years, of which at least one year had been allocated to undergraduate courses of mathematics (e.g., calculus and linear algebra) and mathematics education. They had also taken general education courses addressing issues such as classroom management and diversity, including for example student-questions, students presenting results and the role of whole class discussions for the institutionalisation of knowledge.

For the design of the STEM seminar the learning goals digital tools, programming, mathematical reasoning and mathematics for exploring realistic scenarios in the Swedish mathematics curriculum (Skolverket 2017) were considered, as well as the four categories of twenty-first century skills put forward by Binkley et al. (2012, p. 36) described in Sect. 3.1. Departing from these goals and skills, we found it suitable to use 'micro:bit' (http://microbit.org/) tools for working, developed in the UK for facilitating students' learning of programming, combining computer science with STEM practice in terms of ways of thinking and ways of working. The users may upload Python scripts on the device, which can be used in activities for skills for living in the world such as simulation and exploration of a realistic scenario, and designing new objects. The purpose of letting pre-service teachers experience activities with micro:bit was to prepare them for developing their own innovative lesson plans combining STEM subjects and programming in mathematics classrooms.

Prior to the seminar the pre-service teachers were provided with a tutorial for developing Python code, a link to a Youtube clip about micro:bit, and information about STEM as a teaching strategy for subject integration. They were also asked to develop and submit a computer code that could be used in a mathematics class.

The first half hour of the seminar was allocated to discussions about the role of programming in mathematics education (highlighting the new curriculum text) and the submitted computer codes. The remaining $60 \mathrm{~min}$ were devoted to STEM and its relation to programming, including examples about programming of robots. After an introductory presentation, that clarified the notion of STEM as a way of teaching and learning that facilitates students in becoming engineers and natural scientists, the pre-service teachers paired up and selected one of the micro:bit activities. These included working 'as engineers' to design and 'sell' some 'objects' for teachers for use in mathematics classes, such as step counters and beep tester (see https://www.micro bit.co.uk/iet). The seminar ended with a discussion about the role of mathematics in STEM practice and the students reported about their arguments for using microbit, framed in terms of horizontal and vertical mathematisation, with a critical discussion about micro:bit as pedagogical tool in mathematics education.

As a follow-up home assignment, the pre-service teachers were asked to design lesson plans for STEM education within the existing school organization. The written report to be submitted was expected to comprise the lesson plan and its anticipated implementation, learning goals, role of mathematisation and programming, and reflections about opportunities, concerns, and challenges.

\subsection{Theoretical thematic analysis}

The empirical data used in this paper comprise the preservice teachers' submitted lesson plans, thus entailing a documentary analysis. We followed the recommendation by Braun and Clarke (2006) to employ a theoretical thematic analysis when analysing a data corpus "driven by researchers' theoretical or analytic interest in the area" (Braun and Clarke 2006, p. 84) to answer specific research questions. While thematic analysis is "a method for identifying, analysing and reporting patterns (themes) within data" (Braun and Clarke, 2006, p. 79), a theoretical thematic analysis refers to a process of coding a set of data by fitting it into pre-existing coding frames of themes. Themes for our coding frame were constructed by four twenty-first century skills categories (Binkley et al. 2012, p. 36), the notions horizontal and vertical mathematisation, (Treffers 1987) and Bernstein's (1996) key concepts of classification and framing. A dynamical coding manual was developed with "description of the code, inclusion and exclusion rules for that code, examples of units coded as that code, as well as negative cases" (Syed and Nelson 2015, p. 378) through an iterative process of refining the coding scheme. The coding of the following excerpt from the lesson plan by one of the pre-service teachers (PT10) will serve as an example of this coding procedure.

You will work in a group to identify the function describing how hot water cools down in different containers. The first thing to do is to heat water [description of procedure] Take notes on how the water is cooling down and then create a graph using an appropriate computer program. Develop a Python code that illustrates the function describing how the water cools down in a cup and in a pot [...] You have the following equipment: [list of objects] Presentation: The work should be presented in a report where you describe what you have done and why. The report should include graph [...] Python code [...] The function [...] Show that your function fits the empirical values you have tested $[. .$.$] Try to explain the rate of cooling$ water in different containers using physics [...]. Also 
discuss how exponential functions can be used in other subjects [...] (PT10).

In Table 1 our coding of this excerpt is presented.

According to Syed and Nelson (2015), collaborative researchers, well-articulated coding manuals, rich data, and extensive excerpts along with the analysis presented in the reports, are all quality markers of reliability that we have addressed. Concerning the coding of students' lesson plans in terms of the four categories by Binkley et al. (2012), we used the reliability coefficient Cohen's kappa. The first analysis, applying the coding manual, generated a value of $\kappa=0.76$ with an $84 \%$ agreement, showing an acceptable reliability (Syed and Nelson 2015). The codes not agreed upon in the first analysis were discussed and finally agreed upon. Another quality marker of reliability refers to transparency of the analysis, accomplished by using excerpts alongside the analysis.

\section{Analysis of three lesson proposals}

The result of the analysis of the 19 submitted lesson plan proposals is summarised in Appendix. For the double purpose of illustrating our discussion of the research questions and developing transparency of the method of analysis, three lesson plans were selected to represent both the diversity and commonalities of the 19 proposals. In this section these lesson plans are presented and analysed, with reference to the themes in Table 1. From each proposal the pre-service teacher's description of the activity for the students is presented as well as some excerpts from the commenting text.

\subsection{The latest time you should have a cup of coffee}

Using learning goals from mathematics (methods for solving exponential, quadratic and square root equations) and physics (half-life and decay), pre-service teacher PT8 developed a STEM activity as shown in Fig. 1.

PT8 allocated 2-3 lessons to the activity depending on the students' ability to develop code, with the role of programming being "to deepen the understanding of how to solve exponential equations" (PT8). To be able to solve the tasks provided, the students need to "solve an exponential equation in general, since they need to write the solution in code" (PT8).

Analysis: While the introduction develops a context about caffeine and sleep for mathematical treatment (horizontal mathematisation) which is relevant for STEM education, the first task given resembles a word problem-a type of tasks recognised by students as endorsed in mathematics classrooms (strong external classification). The second question, however, about when the effect is gone, is open as there is no information provided regarding critical levels of caffeine. While there are tables of caffeine content and recommendations for intake available on the Internet, to evaluate the critical caffeine level requires knowledge of chemistry rather than of mathematics (weak external classification).

In the proposal, knowledge of what 'half-life' implies is assumed, giving mathematics the role of a service subject. However, as the argument for the programming component of the activity, as cited above, affords a vertical mathematization to a general mathematical model of the specific context, a focus is set on the 'power of mathematics'. The instruction for students about what kind of reflections they could write down after the activity is unspecified (weak framing of knowledge criteria), as

Table 1 One example from the coding manual for the theoretical thematic analysis

\begin{tabular}{|c|c|c|}
\hline Themes & Arguments for coding & Codes \\
\hline \multicolumn{3}{|l|}{ Binkley et al. (2012) } \\
\hline Ways of thinking & $\begin{array}{l}\text { Explicit instructions which do not emphasise creativity or critical thinking ("The first thing to do } \\
\text { is..."), and explicit questions for students to discuss that promote reflections and metacognition }\end{array}$ & ? \\
\hline Ways of working & $\begin{array}{l}\text { Work in groups, communication of results in reports, descriptions of a working strategy—part of } \\
\text { this category }\end{array}$ & + \\
\hline Tools for working & Computer program, developing Python code-ICT literacy skills & + \\
\hline Skills for living in the world & The instructions do not relate to citizenship, personal or social responsibility & - \\
\hline \multicolumn{3}{|l|}{ Treffers (1987) } \\
\hline Horizontal mathematisation & The rate of cooling water in different containers-the context of cooling & Cooling \\
\hline Vertical mathematisation & Illustrate the function, exponential functions, rate of cooling-main concept exponential function & Exp. Function \\
\hline \multicolumn{3}{|l|}{ Bernstein (1996) } \\
\hline Classification & $\begin{array}{l}\text { Exponential functions (mathematics) are mentioned only in relation to empirical values and } \\
\text { physics }\end{array}$ & Weak \\
\hline Framing & $\begin{array}{l}\text { Even if the instructions for the students leave some specific decisions to them, the framing over } \\
\text { the sequencing and evaluation is strong }\end{array}$ & Strong \\
\hline
\end{tabular}


Fig. 1 The latest time you should have a cup of coffee (PT8) (All excerpts from the students' lesson proposals have been translated from Swedish into English by the authors)
Coffee contains the active substance caffeine. This substance affects our central nervous system adenosine receptors, because the caffeine molecule is similar to the adenosine molecule. What happens when we drink coffee? Adenosine is a neuromodulator calming us down by suppressing arousal and making us tired [...]

The half-life of caffeine is between 3 to 6 hours after the optimum effect aroused. The decay starts 1 hour after consumption, when the optimum effect is aroused.

You drink one cup of coffee with $90 \mathrm{mg}$ caffeine, how long time does it take until:

- a quarter of the dose is left?

- caffeine has no more effect, all of it having left the body?

You decide to go to sleep at 23; what is the latest time you should have a cup of coffee?

Develop a program on your calculator that can determine either the initial [caffeine] value, the time, or the amount of caffeine after a certain time, the other two being given.

Work collaboratively with a friend. Write down your reflections during the work; these shall be presented in a report at the end of the project along with the procedures you have used. well as forms of collaboration (weak framing of authority relations).

Regarding the role of twenty-first century skills, the use of digital tools is required (tools for working, +). The cultural scope and the social relevance of the STEM activity, such as issues of coffee production and consumption (including links to cultural trends), with reference to the role of mathematics for a critical discussion of these issues, is not emphasised (skills for living in the world, $-)$. The desired skills for collaboration are not specified (ways of working, -). The STEM activity includes both a standard word problem requiring little or no creativity, and questions about the effect of critical levels of caffeine that may, due to the lack of information, require innovative methods (ways of thinking, ?).

\subsection{Constructing a pendulum clock}

Pre-service teacher PT12 planned a STEM activity combining mathematics and physics, drawing on broad learning goals such as modelling (mathematics and physics), history of mathematics (mathematics), use of digital tools (mathematics), and laboratory activities (physics). Figure 2 shows excerpts of the information to students provided for the activity.

In this activity students will work in groups of two: "the size of the group enables social interaction and reflection on different ways of thinking" (PT12). The estimated time for the activity is $80-100 \mathrm{~min}$. The activity requires access to adequate equipment, measurement tools and computer resources. From the activity students are "expected to gain more mathematical knowledge by adapting a power function to the measurements using a curve fitting program, such as Excel" (PT12).
Fig. 2 To develop and construct a pendulum clock (PT12) (PT12 here also added a short computer code (trinket.io) for a pendulum cycle with comments.)
- Use a curve fitting program and adjust a power function to your measurement values. Let $y$ be the period in seconds for one complete cycle and $x$ the length of the cord in meters.

Suggestion! Measure the period for 10 cycles and check that your function is correct!

- Compare your power function with the formula for a simple pendulum. [...]

- Build a clock! Make a simple pendulum that has a period of exactly one second. Calculate

theoretically and validate experimentally.

- Code at trinket.io a program that calculates the amount of time passed for a varying number of cycles.

- Examine to what extent theory and practice are consistent? Is the period the same experimentally and theoretically? What factors can affect?

Upon completion of the activity,

you are expected to have basic knowledge of:

- polynomial functions of higher order, strategies for problem solving using digital tools [...]

- harmonic motion as a tool for developing models for describing everyday and technical

phenomena as well as knowledge of how physical problems can be solved by mathematical

modeling, such as the use of power function [...]

\section{Report}

your measurements, results and mathematical reasoning in written form [...] The report should be in the form of an essay and not a laboratory report. The report is assessed by both mathematics and physics teachers. Laboratory skills are assessed during the activity. 
Analysis: The STEM context provided in the activity affords horizontal mathematisation, in coordinating science (the work of Galilei), technology (the history of tools for measuring time) and engineering (construction of a clock). Nevertheless, mathematics tends to play the role of a service subject also in this proposal. Although the learning goals are described explicitly (strong framing over knowledge criteria), what makes the activity different from a traditional physics lab with strong external classification is the programming part and the essay form for the presentation of the results (weak classification), to be assessed by teachers from two school subjects with potentially different evaluation rules (weak framing over evaluation criteria).

The students' work is in many parts of the proposal strongly framed through instructions as a list of procedures to follow. Curve fitting, sometimes described as modelling, is used but the instruction leads the students to apply power functions, later compared with the theoretical model (root function). While the comparison aims to provide students with a conceptual understanding of power functions (vertical mathematisation), there might be other variables than the length of the cord impacting the outcome, as for example mass, not considered in the activity. An instruction with weaker framing regarding which variables to test might have generated other skills.

This proposal involves a number of twenty-first century skills, in particular the category tools for working (+), both excel and programming being used as digital tools in the activity, but also ways of working (+), social interaction and reflection, and ways of thinking $(+)$, comparing, validating. For the activity to become a project in the classical sense (cf.
Knoll, 1997), the product (the clock) would be included in the report, and the work of the students more weakly framed. Reflections on the historical development of time measurement and its role in everyday life as well as in science, adding to the social relevance of the activity, are not required (skills for living in the world, -).

\subsection{Nuclear power plant as energy source}

In the project by PT14 about nuclear power and the danger of radioactivity (Fig. 3), "prospective students are given the opportunity to develop the ability to use scientific knowledge [...] to discuss and make positions for different energy sources" (PT14). The learning goals are taken from science (e.g., energy sources, climate, ecosystem, resource utilization and health) and mathematics (e.g., powers with rational exponents, logarithms and exponential functions, and problem solving using programming).

This project with a clear STEM character by its context, planned for a period of 3 weeks, involves a role-play activity strengthened by the proposal to make "a study visit to a nuclear power plant ". While PT14 writes that "mathematics lessons are devoted to the programming task and the other parts about nuclear power and energy sources are dealt with in the science lessons", he/she also argues that not all mathematics lessons "needed to be devoted to the project" as other learning goals may take longer than expected; the key issue here is "pre-knowledge in programming".

Analysis: While it is somewhat unrealistic that a nuclear plant company would not manage to construct a calculation program themselves, the role as consultants assigned to the
Fig. 3 Nuclear power plant as an energy source (PT14)
In the project, we will in the science lessons investigate how a nuclear power plant works and how it creates energy [...] Furthermore, we will immerse ourselves in the nuclear power plant accident in Chernobyl and develop an understanding of why radioactivity is dangerous to our health. We will also do a workplace visit to a nuclear power plant.

During the project, we will continue working on radioactivity and half-life in mathematics lessons. There you will be assigned the task of coding a program [...]:

You work as a consultant at a computer programming company and have been hired by a company that measures radioactivity. [...] Your task is to develop a program that calculates how the amount of Cesium-137 decreases in a given sample. Cesium-137 [...] has a half-life of 30 years.

The user of the program should be able to enter the amount of radioactive waste measured in one year. Based on this information, the user should be able to select the program to compute the amount remaining at a certain time or the time it takes for a substance to decrease to a certain amount. Test your program using the following information:

- In 1999, the amount of $84 \mathrm{~g}$ of Cesium-137 was measured.

How much will remain in 2020 ?

What year has the original amount decreased to $30 \mathrm{~g}$ ?

- [a similar task as above]

The project will be completed and assessed by a written submission, where you should argue for the advantages and disadvantages of nuclear power as an energy source. Compare nuclear power with other sources of energy [...] 
students may engage them in a STEM context to a greater extent than by just asking them to solve a problem. If the study visit to a nuclear plant can be realised, the authentic component of horizontal mathematisation would be strengthened.

As the underlying mathematical model (exponential function) is pre-defined, explorations for finding adequate models are not promoted; mathematics is also in this example mainly a service subject. The instructions include a statement about testing the developed program but how the students would validate their solutions and control the accuracy is not clear.

Within current mathematics education PT14's argument that "mathematics lessons are devoted to the programming task" may be seen as weak external classification. Similarly to the lesson proposal by PT8, the vertical mathematisation draws on programming to develop a general solution adaptable to the needs of users of the program. This is a way to make the mathematics hidden in devices and programs more visible but it also changes mathematics education, as being able to solve the regular 'word problem' requires both good mathematical and coding skills (weak external classification).

As a computer program is central to the activity, it promotes twenty-first century skills of the category tools for working (+). Being able to use mathematics to consider and evaluate alternative solutions regarding economics, climate, environment etc., for decision making is a skill for the twenty-first century (ways of thinking, + ). This is also closely related to skills for living in the world (+), in taking personal responsibilities regarding issues, such as climate change and depletion of natural resources, into account. While the report requirements are weakly framed they also enhance, with regard to twenty-first century skills, a social relevance of the project work not directly implied by the specific computational tasks that are set up. Skills related to ways of working (-) were not emphasized.

\subsection{Summary analysis}

The pre-service teachers produced comprehensive lesson proposals within STEM contexts drawing on learning goals in different subject syllabi. More than every second pre-service teacher connected mathematics and physics (see Table 3 in Appendix). Only one proposal explicitly suggested more than one STEM subject for the subject integration with mathematics. The wide range of horizontal mathematisation activities in the proposed STEM contexts reflects the multitude of opportunities that exist for developing lessons combining or integrating STEM subjects. Nevertheless, in the proposals the tasks for students often resembled word problems with a strong external classification of school mathematics, as for example You drink one cup of coffee with $90 \mathrm{mg}$ caffeine, how long time does it take until a quarter of the dose is left? and In 1999, the amount of $84 \mathrm{~g}$ of Cesium-137 was measured. How much will remain in 2020? In both examples the underlying mathematical model is assumed to be known to the students, while the STEM contexts are different. This aspect points to the role of mathematics within STEM education as a general application and modelling tool for gaining knowledge and control of processes in different science contexts (horizontal mathematisation; cf. Gravemeijer et al. 2017). The Table 3 in the Appendix illustrates the complexity of capturing ways of thinking with a rather uniform distribution of codes (+) and (-), including some (?).

As part of the activity a few proposals included workplace visits (power plant, weather station, train company), laboratory activities (e.g., pendulum, cooling of water), everyday mathematics (e.g., energy consumption of household appliances, water pressure in a swimming pool) and role-playing activities (e.g., working for the UN) to increase motivation and authenticity.

Our analysis indicated that programming is not always necessary for solving the problem statements but rather served as a tool for developing students' knowledge of mathematical concepts and procedures to a general level (vertical mathematization). Following Gravemeijer et al. (2017), such type of vertical mathematization would cohere with understanding. However, in other lesson proposals pre-service teachers used already defined programs for simulation instead of letting students create their own codes. In terms of tools for working as skills for the twenty-first century, all proposals had a component of programming or used Excel mainly coded as (+).

While many instructions found in the proposals were strongly framed, with detailed directions for what to do, a weakening of the framing could have a stronger potential to promote critical thinking. Others tended to be weakly framed in terms of criteria for the expected knowledge production. Almost all proposals highlighted collaboration in terms of group activities, although with expected ways of collaboration and mathematical communication often being weakly framed. Therefore, it may be difficult to argue that students through the activities would develop tools for working collaboratively. The uniform distribution between the codes (+) and (-) in the category ways of working makes this issue explicit. 
The dominating number of codes (-) within the category of skills for living in the world indicates there are many opportunities to widen the scope of the activities and increase the social relevance by an integration of learning goals focusing on citizenship, life and career, and personal and social responsibility.

\section{Summary of results and discussion}

The claim by Gravemeijer et al. (2017, p. 120) that "we are not currently preparing students for the demands of the twenty-first century workplace and world" generates the question of how to prepare pre-service teachers in mathematics to facilitate their students' development of twentyfirst century skills. This study has explored this question (RQ3), along with the two other research questions (RQ1 and RQ2) with the overall aim to explore potential affordances and constraints of mathematics as an enabler of STEM pedagogies in the perspective of twenty-first century skills, by designing a STEM education seminar for pre-service mathematics teachers and analysing their ensuing lesson plan proposals for STEM education within the existing school organisation. The main results of our analysis of the lesson plan proposals are summarised in Table 2.

The reliability of the coding in the analysis was built on discussions and final agreement between the two authors. However, the findings reported above need to be seen in relation to the design of the explorative study and how the home assignment was constructed. While the study attempted to combine programming, STEM education and the promotion of twenty-first century skills, a seminar with less focus on computer codes and more on STEM education as means for promoting ways of thinking and skills for living in the world, and with an assignment without an obligation to include programming in the activities, might have produced different outcomes. It is therefore not possible to generalise the results beyond the design of the STEM seminar. That some of the outcomes of this study reflect findings from previous research could however be seen as an indicator of external validity. Regarding the scope of the empirical findings, the study has shown that it is possible for current pre-service mathematics teachers, after only a short introduction to STEM education and twenty-first century skills, to design innovative STEM activities with mathematics in the centre. The results also provide a basis for a deepened discussion of potential affordances and constraints of mathematics as an enabler of STEM pedagogies in the perspective of twenty-first century skills.

The activities in the proposals included several characteristics of STEM education as identified in research literature aimed at motivating students to learn science and mathematics (Holmlund et al. 2018) by the use of real world situations (Peters-Burton et al. 2014) and innovative technologies (Holmlund et al. 2018) through problem- and project-based learning (Peters-Burton et al. 2014). However, aiming to support other STEM subjects and placing the context in focus impacts on how the mathematical content and work can be set out in activities supporting the learning of STEM content. Mathematical modelling together with programming was included in most of the lesson proposals. One might hypothesise that mathematical modelling in science, technology and engineering is another term for an integrated STEM education. While an inter- or transdisciplinary integration of mathematics and the other STEM subjects weakens the external classification of mathematics, combining mathematics with programming does not.

It was also noted that mathematics in this context could be seen mainly as a service subject, with the issue of a possible input of the other STEM subjects on mathematics learning not being raised. This generates a critical discussion about the effects on mathematics education itself of such teaching

Table 2 Summary of the answers to the research questions (RQ)

RQ Summarised answers

1 The activities were all designed around context integration, to guide the learning of STEM content using an interdisciplinary or transdisciplinary integration of the STEM activities within the current education system. Some proposals gave very little freedom to the students regarding how to proceed in the activity (strong framing) whereas others gave only little guidance on how the work could or should be done (weak framing)

2 The lesson plans showed a rich variety in the horizontal mathematisation dimension, thus aiming to support other STEM subjects. Including aspects of inquiry-based learning, modelling, and tool-based pedagogy, the students' work was designed in alignment with the pedagogical practice boundary pedagogy for STEM education. Mathematical modelling combined with programming was also frequently included in the lesson proposals to support the learning of STEM content

3 The lesson plans promoted the learning of different twenty-first century skills to different extents. Almost all lesson plans included collaboration and the use of ICT in promoting the skills ways of working and tools for working. Several proposals mediated creativity, problem solving and decision making as ways of thinking. The category skills for living in the world was found in some of the proposals (e.g., climate discussions, energy consumption) 
practice. Regarding project work in school, it had a "remarkable renaissance" in Europe during the 1970s (Knoll 1997; weak external classification) but was later counteracted by school mathematics policy 'movements' arguing for mathematics teaching to focus more on itself (strong external classification) and a move away from a weakly framed pedagogy promoting general competencies. However, recent discussions regarding the need for school education to support STEM topics and twenty-first century skills, suggest crossdisciplinary work at different levels of integration in parallel to competency-oriented curricula for mathematics. This suggestion could lead to a weakly framed teaching of a weakly classified mathematics with implications for the access of knowledge to unprivileged social groups (cf. Jablonka and Gellert, 2012), and potentially turning school mathematics into a service subject. In one of the three analysed proposals a teacher from another subject than mathematics was involved in the project assessment. Such involvement could make the extent to which mathematics supports the learning of other STEM subject(s) more explicit.

Nevertheless, there are several opportunities to develop the lesson plans analysed in this study to strengthen the framing over the selection of knowledge production and evaluation criteria for the purpose of engaging in vertical mathematisation. For example, in the activity Construct $a$ pendulum clock (Fig. 2) "curve fitting" was used. A discussion of mathematics used in digital technology for curve fitting may lead to further vertical mathematisation and involve strongly classified mathematics such as regression analysis and least squares.

The mathematical content in the proposals did relate to some areas suggested by Gravemeijer et al. (2017) as relevant for the future. It was found, however, that the vertical mathematisation opportunities in most cases were connected to generalising aspects of already acquired mathematical concepts and procedures through programming.

The lesson plans would need to be reworked to better afford a generation of twenty-first century skills among students, a possible consequence of the design of the STEM seminar not emphasising these skills enough. Many proposals focused on word and modelling problems used in school mathematics, while modelling work in out of school settings is used for decision making including aspects of critical thinking, problem solving and creativity, not endorsed in school (Frejd and Bergsten 2016; Gainsburg 2013). One suggestion to improve the STEM seminar, regarding the twentyfirst century skills related to ways of thinking and ways of working, is to include readings from educational research on workplace mathematics and professional modelling (e.g., Frejd 2017; Gainsburg 2013). In STEM workplace practices collaboration and communication between different agents are ubiquitous (Frejd and Bergsten 2016). The proposals also indicated weak framing over how students are going to communicate their work to the teachers, including knowledge criteria for assessment.

The use of digital tools has been highlighted as a skill for the twenty-first century. The argument to make mathematics hidden in technology more visible has been used to promote the learning of programming (Gravemeijer et al. 2017). In the proposals, however, most of the problems could be solved without programming, making the coding part just an extra activity. One reason for this outcome may be that the assignment instructions to the pre-service teachers forced the inclusion of programming, an area in which many of them had little experience.

The category skills for living in the world was neglected in the proposals on a deeper level. Coordinating STEM activities with examples from research literature about mathematical literacy concerning features and developments of social realities, might be one opportunity to support these skills. Such an inclusion could increase students' awareness of the role of mathematics in social and political contexts, and students' own experiences of social realities embedded in the STEM activities "might indeed help to change their views of the value of participating in a school mathematics classroom" (Jablonka and Gellert 2012, p. 303).

Finally, the claim by Leung (2018, p. 17) that "the spirit of STEM education is problem-solving" was not mirrored in the lesson plans. The balance between the strengths of framing and classification has implications not only for the promotion of disciplinary content and twenty-first century skills but also for the differentiation between social groups in terms of access to content knowledge. The challenge remains to develop balanced pedagogies for mathematical education that engage students in problem solving in meaningful contexts and support the learning of other subjects that draw on mathematical tools and arguments while maintaining visibility to all students of what counts as legitimate mathematical knowledge.

Acknowledgements Open access funding provided by Linköping University.

Open Access This article is distributed under the terms of the Creative Commons Attribution 4.0 International License (http://creativeco mmons.org/licenses/by/4.0/), which permits unrestricted use, distribution, and reproduction in any medium, provided you give appropriate credit to the original author(s) and the source, provide a link to the Creative Commons license, and indicate if changes were made.

\section{Appendix}

See Table 3. 


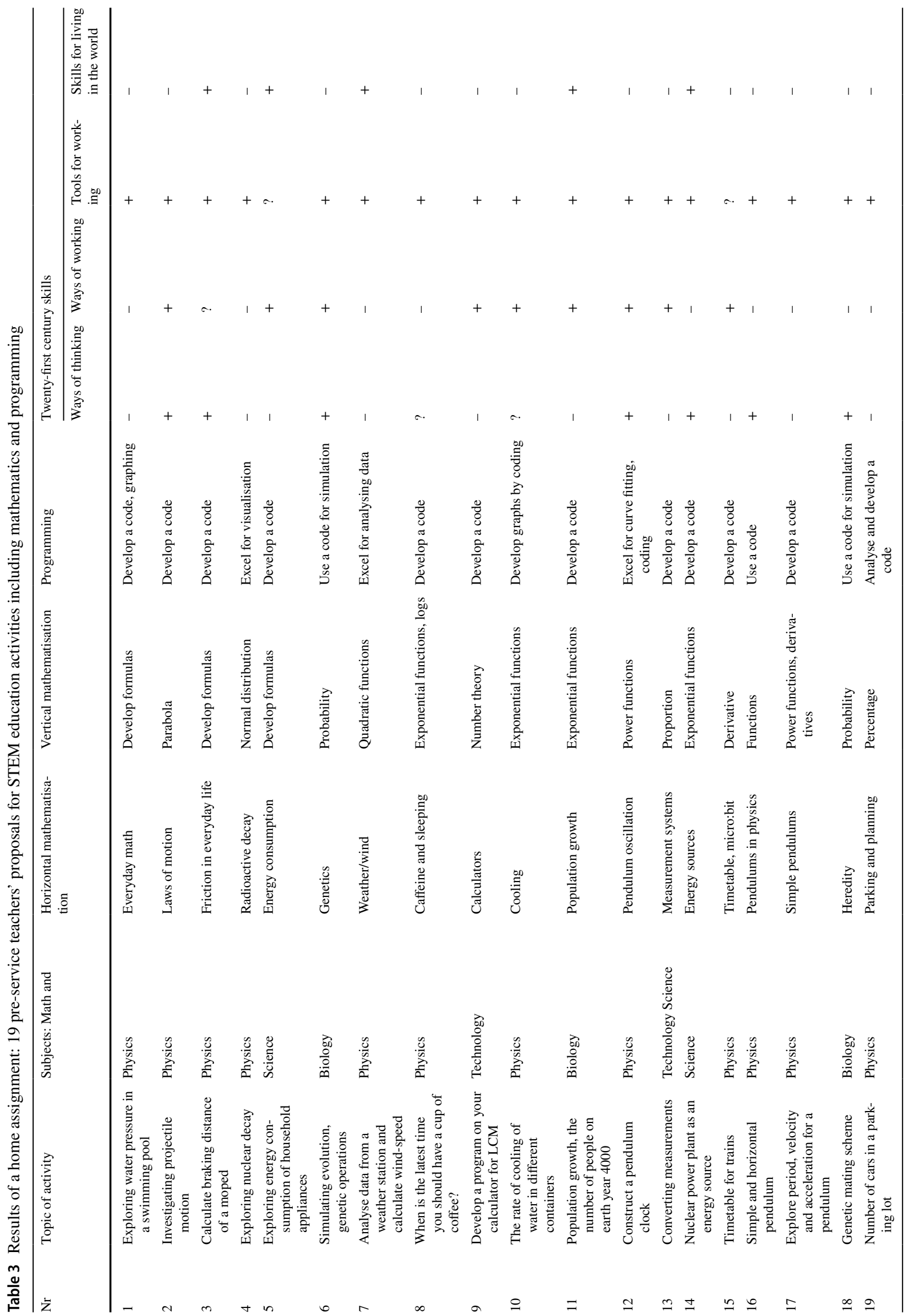




\section{References}

Ananiadou, K., \& Claro, M. (2009). twenty-first century skills and competences for new millennium learners in OECD countries. OECD Education Working Papers, No. 41, OECD Publishing. https://doi.org/10.1787/218525261154

Bergsten, C., \& Jablonka, E. (2013). Mathematics as "Meta-Technology" and "Mind-Power": Views of engineering students. In B. Ubuz, C. Haser, \& M. A. Mariotti (Eds.), Proceedings of the Eighth Congress of the European Society for Research in Mathematics Education (pp. 2286-2295). Antalya: Middle East Technical University.

Bernstein, B. (1996). Pedagogy, symbolic control and identity. Theory, research and critique. London: Taylor and Francis.

Binkley, M., Erstad, O., Herman, J., Raizen, S., Ripley, M., \& Rumble, M. (2012). Defining twenty-first century skills. In P. Griffin, B. McGaw, \& E. Care (Eds.), Assessment and teaching of twenty-first century skills (pp. 17-66). Dordrecht: Springer.

Braun, V., \& Clarke, V. (2006). Using thematic analysis in psychology. Qualitative Research in Psychology, 3, 77-101.

Corlu, M. S., Capraro, R. M., \& Capraro, M. M. (2014). Introducing STEM education: Implications for educating our teachers for the age of innovation. Education and Science, 39(171), 74-85.

English, L. (2016). STEM education: Perspectives on integration. International Journal of STEM Education, 3, 3.

Fitzallen, N. (2015). STEM education: what does mathematics have to offer. In M. Marshman (Ed.), Mathematics education in the margins. Proceedings of MERGA 38, Sunshine Coast, June 28-July 2 (pp. 237-244). Sydney: MERGA.

Frejd, P. (2017). Mathematical modelling as a professional activityLessons for the classroom. In G. A. Stillman, W. Blum, \& G. Kaiser (Eds.), Mathematical modelling and applications: Crossing and researching boundaries in mathematical modelling education (pp. 371-388). Cham: Springer.

Frejd, P., \& Bergsten, C. (2016). Mathematical modelling as a professional task. Educational Studies in Mathematics, 91(1), 11-35.

Gainsburg, J. (2013). Learning to model in engineering. Mathematical Thinking and Learning, 15(4), 259-290.

Gravemeijer, K., Stephan, M., Julie, C., Lin, F. L., \& Ohtani, M. (2017). What mathematics education may prepare students for the society of the future? International Journal of Science and Mathematics Education, 15, 105-123. https://doi.org/10.1007/ s10763-017-9814-6.

Holmlund, T., Lesseig, K., \& Slavit, D. (2018). Making sense of "STEM education" in K-12. International Journal of STEM Education, $5,32$.

Honey, M., Pearson, G., \& Schweingruber, A. (2014). STEM integration in K-12 education: Status, prospects, and an agenda for research. Washington: National Academies Press.

Inglis, M., \& Attridge, N. (2016). Does mathematical study develop logical thinking? Testing the theory of formal discipline. London: World Scientific.
Jablonka, E., \& Gellert, U. (2012). Potentials, pitfalls and discriminations: Curriculum conceptions revisited. In O. Skovsmose \& B. Greer (Eds.), Opening the cage: Critique and politics of mathematics education (pp. 287-307). Rotterdam: Sense Publishers.

Kennedy, T., \& Odell, M. (2014). Engaging students in STEM education. Science Education International, 25(3), 246-258.

Kertil, M., \& Gurel, C. (2016). Mathematical modeling: A bridge to STEM education. International Journal of Education in Mathematics, Science and Technology, 4(1), 44-55.

Knoll, M. (1997). The project method Its vocational education origin and international development. Journal of Industrial Teacher Education, 34(3), 59-80.

Laclau, E. (2007). Why are empty signifiers important in political studies? In E. Laclau (Ed.), Emancipation(s) (pp. 37-49). London: Verso.

Leung, A. (2018). Exploring STEM pedagogy in the mathematics classroom: a tool-based experiment lesson on estimation. International Journal of Science and Mathematics Education. https:// doi.org/10.1007/s10763-018-9924-9.

OECD. (2018). The future of education and skills: Education 2030. Retrieved August 2, 2018, from https://www.oecd.org/educa tion/2030/E2030\%20Position\%20Paper\%20(05.04.2018).pdf

P21, Partnership for twenty-first Century Skills. (2009). Framework for twenty-first century learning. Retrieved February 5, 2018, from http://www.p21.org/our-work/p21-framework

Peters-Burton, E. E., Lynch, S. J., Behrend, T. S., \& Means, B. B. (2014). Inclusive STEM high school design: 10 critical components. Theory Into Practice, 53(1), 64-71. https://doi. org/10.1080/00405841.2014.862125.

Plomp, T. (2013). Educational design research: An Introduction. In T. Plomp \& N. Nieveen (Eds.), Educational design research (pp. 10-51). Enschede: SLO.

Skolverket. (2017). The subject syllabus for mathematics. Retrieved December 19, 2017, from https://www.skolverket.se/ undervisning/gymnasieskolan/laroplan-program-och-amnen -i-gymnasieskolan

STEM. (n.d.). Science, technology, engineering, and mathematics. Wikipedia. Retrieved June 13, 2018, from https://en.wikipedia. org/wiki/Science,_technology,_engineering,_and_mathematics

Stillman, G., Blum, W., \& Biembengut, M. S. (2015). Mathematical modelling in education research and practice: Cultural, social and cognitive influences. Cham: Springer.

Syed, M., \& Nelson, S. C. (2015). Guidelines for establishing reliability when coding narrative data. Emerging Adulthood, 3(6), 375-387.

Treffers, A. (1987). Three dimensions. A model of goal and theory description in mathematics instruction-the Wiskobas Project. Dordrecht: Reidel.

Publisher's Note Springer Nature remains neutral with regard to jurisdictional claims in published maps and institutional affiliations. 